\title{
Quantitative and structural analysis of isotopically labelled natural crosslinks in type I skin collagen using LC-HRMS and SANS
}

\author{
Yi Zhang ${ }^{1}$, Rafea Naffa ${ }^{1 *}$, Christopher J. Garvey ${ }^{2}$, Catherine A. Maidment ${ }^{1}$ and Sujay Prabakar ${ }^{1 *}$ (D
}

\begin{abstract}
Collagen structure in biological tissues imparts its intrinsic physical properties by the formation of several covalent crosslinks. For the first time, two major crosslinks in the skin dihydroxylysinonorleucine (HLNL) and histidinohydroxymerodesmosine (HHMD), were isotopically labelled and then analysed by liquid-chromatography high-resolution accurate-mass mass spectrometry (LC-HRMS) and small-angle neutron scattering (SANS). The isotopic labelling followed by LC-HRMS confirmed the presence of one imino group in both HLNL and HHMD, making them more susceptible to degrade at low pH. The structural changes in collagen due to extreme changes in the $\mathrm{pH}$ and chrome tanning were highlighted by the SANS contrast variation between isotopic labelled and unlabelled crosslinks. This provided a better understanding of the interaction of natural crosslinks with the chromium sulphate in collagen suggesting that the development of a benign crosslinking method can help retain the intrinsic physical properties of the leather. This analytical method can also be applied to study artificial crosslinking in other collagenous tissues for biomedical applications.
\end{abstract}

Keywords: Crosslinks, Isotopic labelling, LC-HRMS, Quantitative analysis, SANS, Collagen structure

\section{Introduction}

Collagen type I is the main component of many loadbearing tissues including skin, bone, tendons, ligaments and dentin in teeth [1]. The biomechanical strength of tissue depends on the organisation of collagen molecules in the fibrils and fibres, which is controlled by the types and amount of proteoglycans and stabilised by covalent crosslinks [2, 3]. Covalent crosslinks are formed between two or three collagen molecules during the fibrillogenesis step of the biosynthesis of collagen [2]. The biosynthesis of collagen starts in the fibroblast cells by the formation of procollagen chains, followed by the oxidation of specific lysine and proline residues into hydroxylysine and hydroxyproline, respectively [1]. Glycosylation of specific hydroxylysine residues occurs, and the collagen molecule is secreted into the extracellular space

\footnotetext{
* Correspondence: rafea.naffa@lasra.co.nz; sujay.prabakar@lasra.co.nz ${ }^{1}$ Leather and Shoe Research Association of New Zealand, P.O. Box 8094 Palmerston North 4472, New Zealand

Full list of author information is available at the end of the article
}

[1]. Further modification by lysyl oxidase convert lysine and hydroxylysine residues to allysine and hydroxyallysine aldehydes respectively, which initiate spontaneous condensation with other amino acid precursors to form covalent crosslinks between collagen molecules [1].

Several types of naturally-occurring covalent crosslinks have been identified in different collagenous materials, including dehydrodihydroxylysinonorleucine (deH-DHLNL), deoxypyridinoline (DPyr), pyridinoline (Pyr), dehydrohydroxylysinonorleucine (deH-HLNL), histidinohydroxylysinonorleucine (HHL) and histidinohydroxymerodesmosine (HHMD), in which deHHLNL, HHL and HHMD are the major crosslinks in the collagen from skins and hides [2-4]. These crosslinks can be classified as reducible and non-reducible [2]. The reducible ones have aldimine bonds that are susceptible to acidic $\mathrm{pH}$, which can be stabilised by reduction using sodium borohydride $\left(\mathrm{NaBH}_{4}\right)$ [5, 6]. Depending on the applications, artificial crosslinkers are used to modify the mechanical properties and 
denaturation temperature of collagenous materials to meet with different purposes [2, 7]. The intermolecular structure of collagen is intrinsically stabilised by the natural crosslinks, however, can also be affected during chemical crosslinking [8-10]. One of the largest industrial applications of skins is the manufacturing of leather, which involves both organic and inorganic crosslinking reagents to increase the denaturation temperature and retain its flexibility and organoleptic properties close to the original skins [7]. Chromium sulphate was reported to change the collagen structure significantly while causing a decrease in the overall quantity of natural crosslinks in skin, which would potentially deteriorate the mechanical strength of the final product [10]. The development of insightful analysis of the natural crosslinks in skin collagen and its interaction with artificial crosslinks is therefore, beneficial for the development of greener processing technologies.

Several methods have been developed to analyse collagen crosslinks, including isotopic labelling [11, 12], chromatography $[4,6,13,14]$ and spectroscopy [15-18]. Although there are a large number of methods for crosslink analysis, only one method has been successfully applied for the characterisation and quantitative analysis of all known natural crosslinks in collagen using liquidchromatography coupled with high-resolution accuratemass mass spectrometry (LC-HRMS). This method allows for high-resolution detection of the monoisotopic mass of deH-HLNL, HHL and HHMD the major skin crosslinks $[3-6,10,19]$.

The structure of collagen has been analysed using small-angle neutron scattering (SANS) based on contrast variation between hydrogen and deuterium, as the coherent neutron scattering length $\left(b_{c o h}\right)$ of deuterium $\left(b_{c o h}=6.671 \mathrm{fm}, \mathrm{fm}=10^{-15} \mathrm{~m}\right)$ is largely different from hydrogen $\left(b_{c o h}=-3.739 \mathrm{fm}\right)[20-26]$. White et al. reported the first neutron diffraction of collagen using rat tail tendon in $\mathrm{H}_{2} \mathrm{O}$ and $\mathrm{D}_{2} \mathrm{O}$ [21]. Wess et al. deuterated deH-DHLNL in rat tail tendon using $\mathrm{NaBD}_{4}$ to study the position of the crosslinks in combination with a proposed collagen model [22]. Other studies included the labelling of deH-DHLNL in tendon and bone to study the collagen structure using neutron diffraction [12, 22-25].

To understand the effect of natural crosslinks on the collagen structure of skin we need to understand the interactions between natural and artificial crosslinks. In this work, we have for the first time analysed two major reducible crosslinks (deH-HLNL and HHMD) in skin as well as their deuterium-labelled form, using a combination of LC-HRMS and SANS. This analytical method can also be applied to other collagenous biological tissues to further understand the crosslinks, and help improve the sustainability of the manufacturing industry.

\section{Experimental methods}

\subsection{Materials and methods}

2.1.1 Labelling of collagen natural crosslinks and processing of skin

Raw sheep skin sections were treated for $24 \mathrm{~h}$ with $3 \%$ (wt.\% of the skin, same below) sodium borohydride, sodium borodeuteride or kept untreated, named as reduced, labelled and control, respectively. Samples were collected after the reduction reaction ("Raw" stage) and the rest were processed through the following steps: (i) unhairing; (ii) pickling (acidifying); (iii) degreasing; (iv) crosslinking. Detailed processing methods were described in the Supporting Information (Additional file 1). Samples were collected at step ii ("Pickled" stage) and iv ("Crosslinked" stage). All samples were kept at $4{ }^{\circ} \mathrm{C}$ prior to further analysis.

\subsubsection{Analysis of collagen crosslinks by liquid- chromatography high-resolution accurate-mass mass spectrometry (LC-HRMS)}

Natural crosslinks in skin samples were analysed based on a previously published method by Naffa et al. [6, 27] Briefly, dry samples were weighed (20-40 mg) and rehydrated in a $1 \mathrm{~mL}$ of phosphate buffered saline $(0.15 \mathrm{M}$ sodium chloride, $0.05 \mathrm{M}$ sodium phosphate $\mathrm{pH}$ 7.4). Control samples were analysed both as-prepared and stabilised (named as "stabilised control"). For stabilising the control samples, sodium borohydride $\left(\mathrm{NaBH}_{4}\right)$ was dissolved in 1 $\mathrm{mM}$ sodium hydroxide at $4{ }^{\circ} \mathrm{C}$ then added to give a (1:30) ratio of sodium borohydride to dry skin and incubated at $25^{\circ} \mathrm{C}$ for $24 \mathrm{~h}$. The reduction was stopped by adjusting the $\mathrm{pH}$ to 3.0 using glacial acetic acid then reduced samples washed three times with water and lyophilized. The lyophilized reduced samples were hydrolysed in $3 \mathrm{~mL}$ of $6 \mathrm{M}$ $\mathrm{HCl}$ containing $3 \%$ phenol at $105^{\circ} \mathrm{C}$ for $24 \mathrm{~h}$ and the resulting hydrolysates were then dried and rehydrated in $2 \mathrm{~mL}$ of water. Prior to extraction of the crosslinks using CF-11 column, $20 \mu \mathrm{L}$ was removed from each sample for hydroxyproline analysis. The remaining samples were subjected to CF-11 column to remove the free amino acids and retain the crosslinks. Crosslinks were eluted by water which was removed by SpeedVac (SavantTM SPD131DDA, ThermoFisher). The dried crosslinks were then dissolved in $1.0 \mathrm{~mL}$ of water. Samples were injected into a Cogent Diamond Hydride HPLC column (150 $\mathrm{mm} \times 2.1 \mathrm{~mm}$; particle size, $2.2 \mu \mathrm{m}$; pore size $100 \AA$ ) purchased from Microsolv Technology, Leland, NC, USA. Water was solvent A and $80 \%(\mathrm{v} / \mathrm{v})$ acetonitrile in water was solvent B both containing formic acid $(0.1 \% \mathrm{v} / \mathrm{w})$. Gradient elution program started with $90 \%$ of solvent B in $0 \mathrm{~min}, 5 \%$ of solvent B in $2 \mathrm{~min}$ then returned to $90 \%$ of solvent $B$ at $5.0 \mathrm{~min}$ and column was equilibrated for 5.0 min prior to next injection. Total run time was $10 \mathrm{~min}$, flow rate was $0.3 \mathrm{~mL} / \mathrm{min}$, and column temperature $25^{\circ} \mathrm{C}$. 
Crosslinks eluted from the column were detected using Q-Exactive hybrid quadrupole-orbitrap high-resolution accurate-mass spectrometry (Thermo Fisher Scientific, San Jose, USA). A positive ion mode was used with capillary temperature of $320^{\circ} \mathrm{C}$ and auxiliary gas heater temperature of $350{ }^{\circ} \mathrm{C}$. The spray voltage was $+3.3 \mathrm{kV}$, sheath gas pressure was 10 arbitrary units (a.u.) and the flow rate of sheath gas $\left(\mathrm{N}_{2}\right)$ was 10 (a.u.). The total ion chromatograms (TIC) produced were examined and quantitation was carried out using Thermo Xcalibur 3.0 software (Thermo Fisher Scientific, San Jose, USA). Hydroxylysinonorleucine (HLNL), histidinohydroxylysinonorleucine (HHL) and histidinohydroxymerodesmosine (HHMD) concentrations were determined then normalized to the collagen content of the sample which was calculated based on their hydroxyproline content [27-29].

\subsubsection{Small-angle neutron scattering (SANS)}

SANS experiments were performed on the QUOKKA instrument [30] at the OPAL reactor (Australian National
Science and Technology Organisation, Lucas Heights, Australia). To interrogate length-scales of interest a range of scattering vectors, $\mathrm{q}, 8 \times 10^{-4}<\mathrm{q}<0.4 \AA^{-1}$, where $\mathrm{q}=(4 \pi /$ $\lambda)^{*} \sin \theta, \lambda$ is wavelength of the neutrons and $2 \theta$ is the scattering angle were probed using 3 different instrument configurations:

(1) sample-to-detector distance $=2 \mathrm{~m}$, wavelength $=5.0$ $\AA$, exposure time $=3 \mathrm{~min}$;

(2) sample-to-detector distance $=14 \mathrm{~m}$, wavelength $=$ $5.0 \AA$, exposure time $=20 \mathrm{~min}$;

(3) sample-to-detector distance $=20 \mathrm{~m}$, lens optics, wavelength $=8.1 \AA$, exposure time $=30 \mathrm{~min}$;

The size of neutron beam was $10 \mathrm{~mm}$ in diameter for all measurements. Skin samples were cut into squares with size of $10 \times 10 \mathrm{~mm}$ and kept hydrated in quartz cells (1 $\mathrm{mm}$ in thickness, $20 \mathrm{~mm}$ in diameter) for the measurements. The isotropic 2D SANS data was reduced to an absolutely scaled $1 \mathrm{D}$ form using the NIST SANS reduction

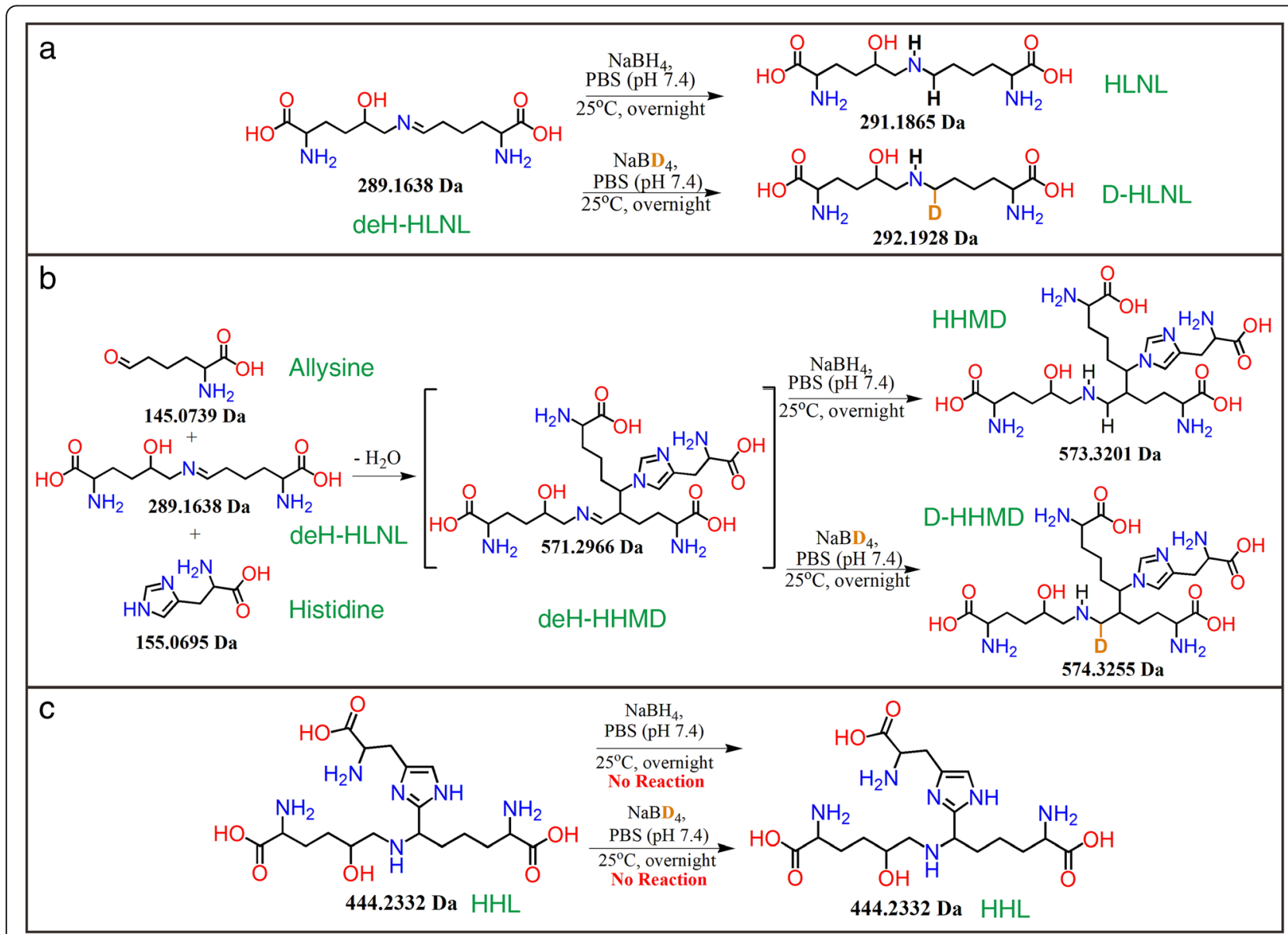

Fig. 1 Proposed reduction mechanism of the three natural crosslinks in collagen using $\mathrm{NaBH}_{4}$ or $\mathrm{NaBD}_{4}$. a The $\mathrm{C}=\mathrm{N}$ double bond in deH-HLNL is reduced to $\mathrm{CH}-\mathrm{NH}$ or $\mathrm{CD}-\mathrm{NH}$ in HLNL or D-HLNL, respectively. $\mathbf{b}$ The $\mathrm{C}=\mathrm{N}$ double bond in deH-HHMD can be reduced to form HHMD. However, the existence of deH-HHMD in vivo is yet debatable; it may be composed from deH-HLNL, histidine and allysine ex vivo during reduction. $\mathbf{c}$ HHL is not reducible (no reaction with $\mathrm{NaBH}_{4}$ or $\mathrm{NaBD}_{4}$ ). Theoretical molecular weight is calculated and presented below each molecule [34-36] 


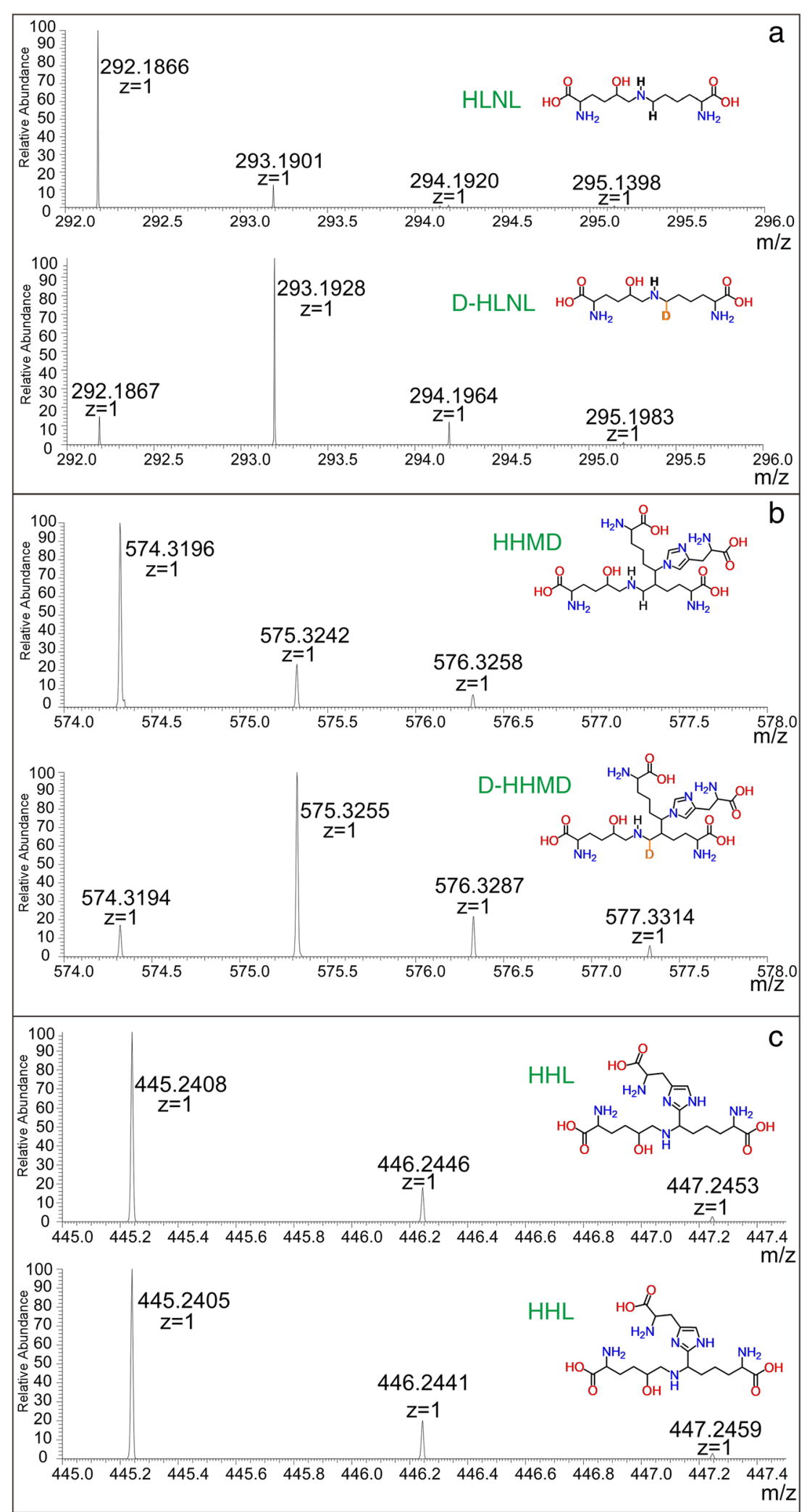

Fig. 2 (See legend on next page.) 
(See figure on previous page.)

Fig. 2 Mass spectra of reduced and labelled crosslinks. a An increase in mass by $\sim 1$ Da is observed in D-HLNL in comparison to HLNL, showing that there is one deuterium attached to each molecule. $\mathbf{b}$ Similarly, HHMD also shows a difference of $\sim 1 \mathrm{Da}$ compared to D-HHMD. $\mathbf{c} H H L$ is not reducible and confirmed by similar mass spectra from both $\mathrm{NaBH}_{4}$ and $\mathrm{NaBD}_{4}$ treated samples. The experimental mass of ionized fragments was presented with each peak and with the corresponding crosslink structure

macros [31] in the Igor software package (version 6.3.7.2, Wavemetrics, USA) adapted for the QUOKKA instrument. The reduced 1D data was analysed using an inhouse developed fitting software $[32,33]$. The relative diffraction peak intensities were calculated as $R_{i / j}=A_{i} / A_{j}$, where $A_{i}$ and $A_{j}$ is the area of peak $i$ and $j$. Further information about SANS data analysis was described in the Supporting Information (Additional file 1).

\section{Results and discussion}

3.1 Characterization of natural crosslinks in skin collagen: isotopic labelling using $\mathrm{NaBD}_{4}$ and mechanism of HHMD formation

The proposed mechanisms of the isotopic labelling of natural crosslinks are listed in Fig. 1 [34-36]. When treated with $\mathrm{NaBH}_{4}$, the $\mathrm{C}=\mathrm{N}$ double bond in deH-HLNL will be transformed to a CH-NH single bond in HLNL (Fig. 1a), which imparts improved stability in acidic conditions to the crosslinks $[26,37,38]$. Similarly, $\mathrm{NaBD}_{4}$ reduction results in a labelled single bond (CD-NH) with one deuterium atom attached to each molecule [12]. The mechanism of the formation of histidinohydroxymerodesmosine (HHMD) although contentious has been proposed to follow either (Fig. 1b): (a) formed by the reduction of $\mathrm{C}=\mathrm{N}$ double bond of dehydrohistidinohydroxymerodesmosine (deH-HHMD) existing in vivo [34-36]; (b) formed from precursors ex vivo during reduction. The deH-HLNL, histidine and allysine form HHMD through Michael addition under basic conditions during $\mathrm{NaBH}_{4}$ reduction [34-36]. Therefore, the labelling with $\mathrm{NaBD}_{4}$ will allow us to verify the proposed mechanisms for HHMD. Histidinohydroxylysinonorleucine (HHL) (Fig. 1c) does not contain a reducible $\mathrm{C}=\mathrm{N}$ double bond, so no reaction is expected to occur between $\mathrm{HHL}$ and $\mathrm{NaBH}_{4}$ or its deuterated form.

The mass spectra of HLNL, D-HLNL (D-, prefix for deuterated molecules, same below), HHMD, D-HHMD and HHL are presented along with the molecular structures (Fig. 2). The deuterium-labelled natural crosslinks in skin collagen were isolated and detected to confirm their structures. For HLNL and D-HLNL, the theoretical masses were $291.1865 \mathrm{Da}$ and $292.1928 \mathrm{Da}$, showing exact matches with the experimental monoisotopic masses, i.e., $292.1866 \mathrm{~m} / \mathrm{z}(\mathrm{z}=1$, same below) for HLNL and $293.1928 \mathrm{~m} / \mathrm{z}$ for D-HLNL (Fig. 2a). The mass difference between HLNL and D-HLNL confirms the presence of one $\mathrm{C}=\mathrm{N}$ double bond in deH-HLNL (theoretical monoisotopic mass: $288.1683 \mathrm{~m} / \mathrm{z}$ ) that can be reduced by $\mathrm{NaBH}_{4}$ or $\mathrm{NaBD}_{4}$. This is also in excellent agreement with previous reports, where Bailey et al. reduced deH-HLNL using sodium borotriteride $\left(\mathrm{NaBT}_{4}\right)$ and partially identified it by mass spectrometry $[26,39]$. The results for HHMD and D-HHMD also indicated the successful labelling of HHMD (Fig. 2b): mass spectra showed $574.3196 \mathrm{~m} / \mathrm{z}$ for HHMD and $575.3255 \mathrm{~m} / \mathrm{z}$ for D-HHMD, while the calculated monoisotopic masses being $573.3201 \mathrm{Da}$ and $574.3255 \mathrm{Da}$, respectively. Although the in vivo structure of HHMD remains debatable, this observation has made a solid step forward to the understanding of HHMD crosslink. The variance of experimental masses between HHMD and D-HHMD revealed that, only one double bond is reducible during the formation of HHMD. This means that, it could be an intact molecule with one $\mathrm{C}=\mathrm{N}$ double bond in vivo (deHHHMD) or, amongst the possible groups of precursors, there is only one reducible $\mathrm{C}=\mathrm{N}$ double bond in each group. Our finding also agrees with the three-precursor mechanism proposed by Eyre et al., suggesting a threestep mechanism: (i) base-catalysed aldol addition between allysine and deH-HLNL to form an $\alpha, \beta$-unsaturated aldimine; (ii) base-catalysed Michael addition between the aldimine and histidine; (iii) reduction of the aldimine crosslink [34].

On the other hand, as a non-reducible crosslink, the unreacted HHL was confirmed by the equivalent monoisotopic masses of ionized HHL $(445.2405 \mathrm{~m} / \mathrm{z}$ and $445.2408 \mathrm{~m} / \mathrm{z}$ ) from both $\mathrm{NaBH}_{4}$ and $\mathrm{NaBD}_{4}$ treated samples (Fig. 2c). Mass spectra were also collected from control samples without further stabilisation, and the peaks were found similarly strong for HHL crosslink, however both HLNL and HHMD were much lower (Fig. 3). This confirmed the susceptibility of the $\mathrm{C}=\mathrm{N}$ double bond in reducible crosslinks to acid hydrolysis during mass spectrometry sample preparations. Based on the highresolution mass spectral results, the natural crosslinks can be quantified to provide detailed information about their changes during processing, which in turn affects the collagen structure and skin properties significantly.

\subsection{Quantification of natural crosslinks in skin collagen: relationship with $\mathrm{pH}$ and crosslinking conditions}

The quantity of natural crosslinks was calculated from the integrated peak areas of the high-resolution mass spectra using our previously published protocols [6], and compared across each processing stages (Fig. 3). In the control samples, reducible crosslinks (HLNL and HHMD) were almost eliminated due to the severe acidic 


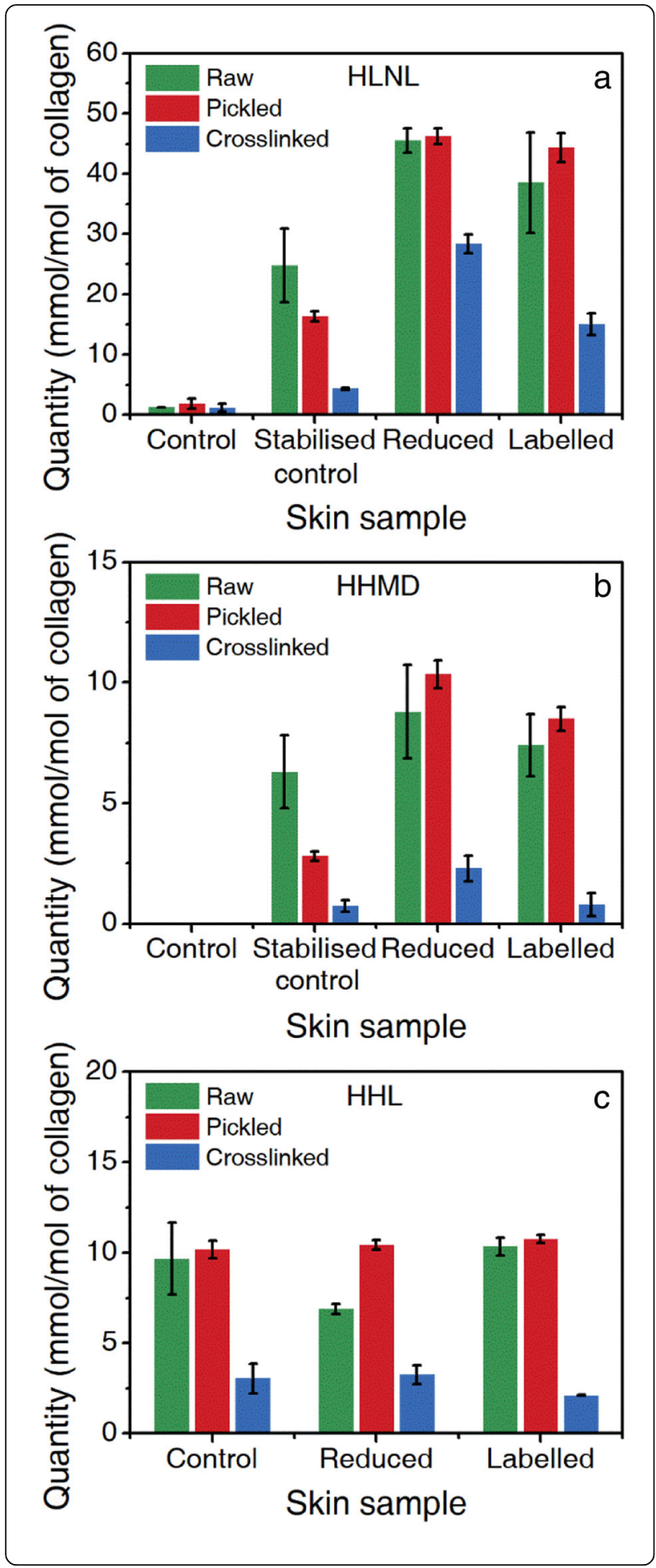

Fig. 3 Concentration of natural crosslinks in skin sample at different processing stages. $\mathbf{a}, \mathbf{b}$ Control samples measured as-prepared showed no HLNL and HHMD due to the strong acidic condition during hydrolysing step of sample preparation (to quantify HLNL and HHMD in control samples, stabilisation using $\mathrm{NaBH}_{4}$ prior to acid hydrolysis is required). HLNL and HHMD in stabilised control showed decreases in quantity when processed from raw to pickled stage. Further decreases were observed from pickled to crosslinked stage. c HHL can be observed in control, reduced and labelled skin samples, with no decrease during pickling but a significant decrease when crosslinked

condition during the hydrolysing step of the sample preparation for LC-HRMS analysis (Fig. 3a and b). Therefore, $\mathrm{NaBH}_{4}$ reduction was added to the sample preparation step prior to the hydrolysis of control samples, to stabilise the crosslinks for quantification at difference processing stages. The stabilised control sample showed a decrease in the amount of HLNL and HHMD from raw to pickled stage as expected, because of the low pH (1.5-2.0) conditions during pickling (acidification). After chrome tanning, the natural crosslinks decreased again, which is in agreement with our previous observation [10].

For $\mathrm{NaBH}_{4}$ reduced and $\mathrm{NaBD}_{4}$ labelled samples, both HLNL and HHMD remained intact during the pickling step, indicating the uniform penetration during the reduction and stabilisation step through the skin matrix (Fig. 3a and b). No decrease in quantity was observed for the HHL during pickling as it is stable in acidic conditions (Fig. 3c). However, chrome tanning causes a decrease in the quantity of all three natural crosslinks. During chrome tanning, the carboxylate $\left(-\mathrm{COO}^{-}\right)$groups of aspartic (Asp) and glutamic (Glu) acid residues of collagen are bonded covalently [7], causing significant structural changes in collagen [40, 41]. Similarly, the removal of structure stabilizing natural crosslinks can also cause changes in the collagen structure [3, 42]. The interaction between natural and artificial crosslinks can therefore be studied by analysing the structural changes of collagen. Using neutron scattering technique, the contrast variation between $\mathrm{NaBD}_{4}$ labelled and $\mathrm{NaBH}_{4}$ reduced crosslinks will highlight the changes caused by these crosslinks. Also, since the contribution of chromium $\left(b_{c o h}=3.635 \mathrm{fm}\right)$ to the coherent neutron scattering length density is much lower than carbon $\left(b_{c o h}=6.646 \mathrm{fm}\right)$ and deuterium $\left(b_{c o h}=6.671 \mathrm{fm}\right)$, it doesn't dominate the intensity of the diffraction signal as which in X-ray scattering analyses, enabling us to resolve the structural variations of collagen relating to the natural crosslinks [20, 43].

\subsection{Structural analysis of skin collagen: interplay between natural and artificial crosslinks}

For the SANS analysis, samples were collected at similar stages to the corresponding natural crosslink analyses. 

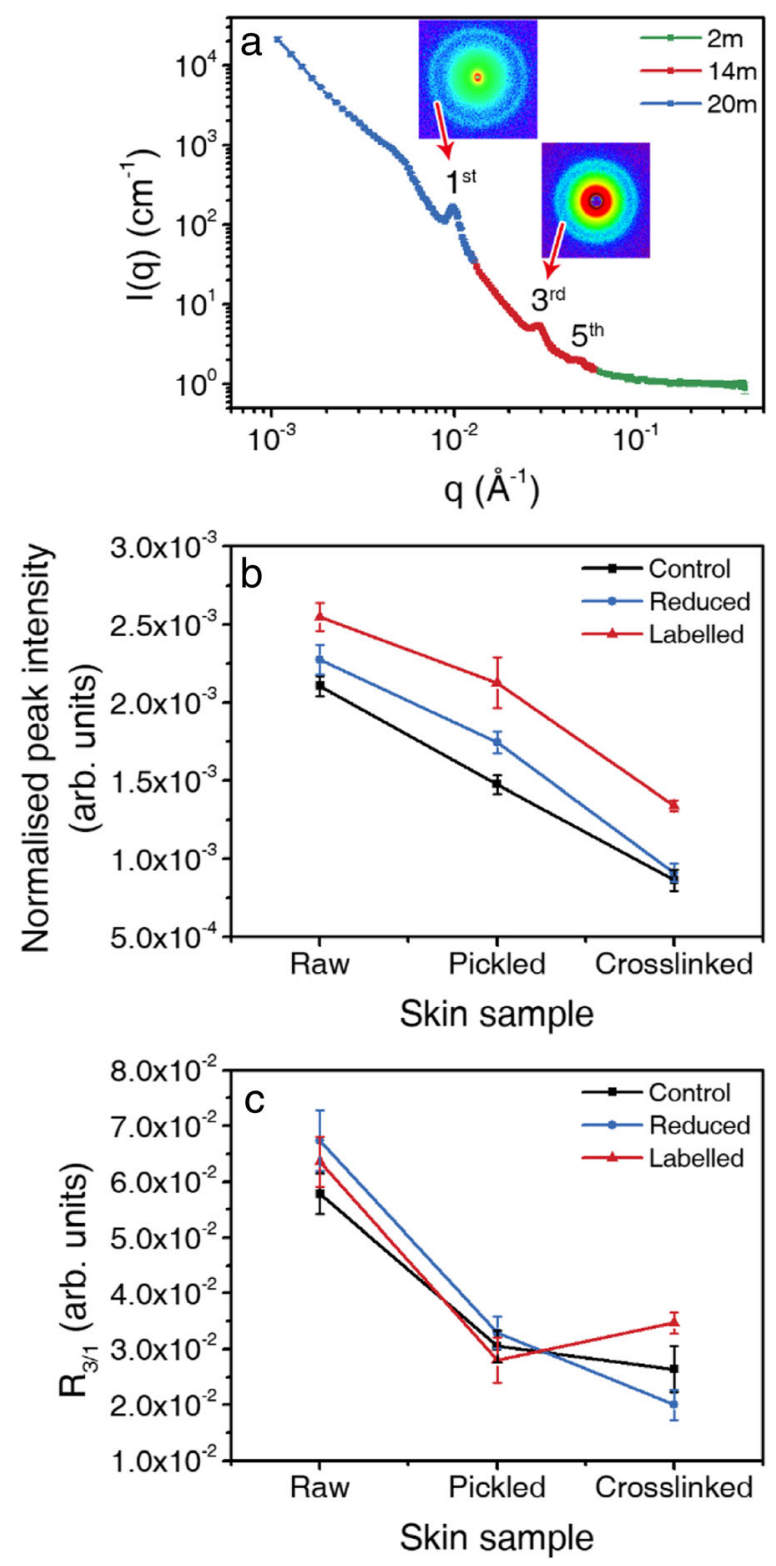

Fig. 4 Results from SANS analysis on skin samples. a 2D SANS scattering pattern of collagen in non-reduced raw skin collected at sample-to-detector distances of $2 \mathrm{~m}, 14 \mathrm{~m}$ and $20 \mathrm{~m}$. The corresponding 1D q-plots obtained by radial averaging of the azimuthal intensity of the $2 \mathrm{D}$ patterns are also shown. The diffraction peaks from collagen in skin were labelled by orders (1st, 3rd and 5th). $\mathbf{b}$ Average of normalised intensity of the 1st and 3rd order diffraction peaks decreased from raw to crosslinked stage. c Relative intensity of the $3 \mathrm{rd}$ to 1 st order diffraction peaks $\left(R_{3 / 1}\right)$ decreased from raw to pickled stage while showing different trends from pickled to crosslinked stage between labelled and non-labelled skin samples

The characterisation and quantification of natural crosslinks using LC-HRMS showed consistent trends for reduced compared to labelled skin samples, which allows us to highlight their contribution to structural changes of skin collagen, based on contrast variation between deuterium and hydrogen. Typical SANS patterns of collagen were observed from our skin samples (Fig. 4a). The diffuse feature $\left(3 \times 10^{-3}<\mathrm{q}<7 \times 10^{-3} \AA^{-1}\right)$ is assigned to an instrumentally smeared form factor oscillation originating from the collagen fibrils, while the rings are well resolved to the long-range ordered intermolecular axial packing of collagen. Collagen in skin is less oriented compared to tendon and thus exhibits diffraction rings instead of narrow bands [21].

Radial averaging of all directions around the centre of the neutron beam resulted in the q-plots (Fig. 4a), followed by the fitting of the baseline and the peaks for intensities. Excluding the diffraction peaks, while the low $\mathrm{q}$ region (blue and red line) can be attributed to the form factor scattering, the plot at high q region (green line) was almost flat. The high background scattering is due to the significant incoherent scattering of hydrogen in the water molecules in fully hydrated leather samples [43]. The 1st order diffraction of skin collagen is observed to be much stronger than the 3rd and 5th order, similar to tendon collagen [12]. The distinct peaks (1st and 3rd) were then normalised and averaged to represent the overall neutron diffraction intensity of the collagen samples (Fig. 4b). Such intensity changes can reflect multiple factors of the collagen structure: the scattering contrast in the matrix, the distribution of nuclei, and the long-range regularity of the repeat unit [20]. The overall intensity in the labelled samples were constantly higher than that of control and reduced samples (Fig. 4b), indicating an enhanced scattering contrast due to the introduction of deuterium into the matrix [43]. From raw to pickled skins, normalized peak intensity decreased in all samples. This may be related to the removal of noncollagenous component within the collagen matrix during the treatments, leading to a more disordered collagen structure thereby increasing the destructive interference of the coherent neutron scattering [2, 44]. After Cr crosslinking, normalized peak intensity showed another decrease across all samples. It suggested a connection between the disrupted intermolecular structure and the sharp decrease in quantity (60 to $80 \%$ ) of the natural crosslinks during this processing step.

Table 1 Collagen D-periodicity at different processing stages in control, reduced and labelled skin samples. The D-period decreased for all samples starting from raw to the pickled stage, then increased at the crosslinked stage

\begin{tabular}{llll}
\hline D-period $(\mathrm{nm})$ & Control & Reduced & Labelled \\
\hline Raw & $64.2 \pm 0.1$ & $64.2 \pm 0.1$ & $64.2 \pm 0.1$ \\
Pickled & $62.2 \pm 0.2$ & $61.9 \pm 0.1$ & $61.2 \pm 0.2$ \\
Crosslinked & $64.1 \pm 0.3$ & $63.7 \pm 0.2$ & $63.8 \pm 0.1$ \\
\hline
\end{tabular}


The changes in diffraction peak intensities of collagen are further investigated as their relative intensity to understand the crosslinking events (Fig. 4c) [12, 45]. During the pickling process, skin samples were treated with salt and acid, leading to a more compact molecular structure according to the decreased axial packing periodicity $(D$ period) of collagen (Table 1). The intermolecular structure changes were also observed as the decreased relative intensity of the 3 rd to 1 st order diffraction peaks $\left(R_{3 / 1}\right)$. Decrease in $\mathrm{pH}$ would disrupt the electrostatic environment for hydrogen bonding of the amino acid residues in collagen molecules, resulting in the variations of the intermolecular organisation [46]. When crosslinked, the amino acid residues in telopeptidyl region would be covalently bonded and the axial gaps between molecules were found to expand (Table 1). This is consistent with previous observations [10]. However, the labelled sample exhibited an opposite trend in $R_{3 / 1}$ compared to the reduced sample and the control sample (Fig. 4c). This implies a strong interference of $\mathrm{Cr}$ on the natural crosslinks, highlighted by the contrast between deuterium labelled vs. non-labelled natural crosslinks [47]. The mechanism remains unclear, but it is indirectly supported by the decreasing trend in the detectable quantity of the natural crosslinks (Fig. 3). The positive effects on the property of skin by the natural crosslinks may therefore be "masked" by a destructively high offer of artificial crosslinkers, leading us to reconsider about optimising the processing method in the industry to achieve improved properties in the final product.

\section{Conclusions}

A combination of quantitative (LC-HRMS) and structural (SANS) analysis was used to study the natural crosslinks (HLNL, HHMD and HHL) in collagen during the processing of skin into leather. HRMS results showed a $60-80 \%$ decrease in the concentration of natural crosslink due to the artificial crosslinking using chromium sulphate. This is also supported by the different trends of the changes in SANS peak intensities between labelled and non-labelled natural crosslinks. The results highlighted strong interactions between artificial and natural crosslinks, which can cause the loss of intrinsic physical properties in the final leather products. Understanding the relationship between artificial and natural crosslinks can guide us towards the use of a more benign chemistry of producing leather in the future.

\section{Supplementary information}

Supplementary information accompanies this paper at https://doi.org/10. 1186/s42825-019-0012-x.

Additional file 1. Supporting Information. (DOCX $35 \mathrm{~kb}$ )

\section{Abbreviations}

deH-DHLNL: Dehydrodihydroxylysinonorleucine; deH-

HHMD: Dehydrohistidinohydroxymerodesmosine; deH-
HLNL: Dehydrohydroxylysinonorleucine; D-HHMD: Deuterated histidinohydroxymerodesmosine; D-HLNL: Deuterated dihydroxylysinonorleucine; HHL: Histidinohydroxylysinonorleucine; HHMD: Histidinohydroxymerodesmosine; HLNL: Dihydroxylysinonorleucine; LC-HRMS: Liquid-chromatography high-resolution accurate-mass mass spectrometry; $R_{3 / 1}$ : Relative intensity of the 3rd to 1 st order diffraction peaks; SANS: Small-angle neutron scattering

\section{Acknowledgements}

S.P., R.N. \& Y.Z. would like to thank Australia's Nuclear Science and Technology Organisation (ANSTO) for access to beam-time on the QUOKKA beamline. Y.Z. would like to thank the International Union of Leather Technologists and Chemists Societies (IULTCS)/Lear Corporation for the 2018 Young Leather Scientist Grant.

\section{Authors' contributions}

YZ, RN, CG and SP contributed to the SANS experiments and data analyses. CM and RN conducted the LC-HRMS analyses. All authors contributed equally to the writing of the manuscript. All authors read and approved the final manuscript.

\section{Funding}

The research was financially supported by the Ministry of Business, Innovation and Employment (MBIE) through LASRA Strategic Science Investment Funding (SSIF). Grant Number LSRX1801.

Availability of data and materials

Detailed method for leather processing and SANS data analysis are included in the supporting information.

\section{Competing interests}

The authors declare that they have no competing interests.

\section{Author details}

${ }^{1}$ Leather and Shoe Research Association of New Zealand, P.O. Box 8094, Palmerston North 4472, New Zealand. ${ }^{2}$ Australian Centre for Neutron Scattering, ANSTO, Lucas Heights, NSW 2234, Australia.

Received: 28 May 2019 Accepted: 2 September 2019

Published online: 31 October 2019

\section{References}

1. Hulmes DJ. Collagen diversity, synthesis and assembly, Collagen. Boston: Springer; 2008. p. 15-47.

2. Fratzl P. Collagen: structure and mechanics, an introduction, Collagen. Boston: Springer; 2008. p. 1-13.

3. Naffa R, Maidment C, Ahn M, Ingham B, Hinkley S, Norris G. Molecular and structural insights into skin collagen reveals several factors that influence its architecture. Int J Biol Macromol. 2019;128:509-20.

4. Naffa R, Watanabe S, Zhang W, Maidment C, Singh P, Chamber P, Matyska MT, Pesek JJ. Rapid analysis of pyridinoline and deoxypyridinoline in biological samples by liquid chromatography with mass spectrometry and a silica hydride column. J Sep Sci. 2019;42(8):1482-8.

5. Naffa R, Edwards PJ, Norris G. Isolation and characterization of collagen type I crosslink from skin: high-resolution NMR reveals diastereomers of hydroxylysinonorleucine crosslink. Amino Acids. 2019;20:1-11.

6. Naffa R, Holmes G, Ahn M, Harding D, Norris G. Liquid chromatographyelectrospray ionization mass spectrometry for the simultaneous quantitation of collagen and elastin crosslinks. J Chromatogr A. 2016;1478:60-7.

7. Covington AD. Tanning chemistry: the science of leather. Cambridge: Royal Society of Chemistry; 2009

8. Paul RG, Bailey AJ. Chemical stabilisation of collagen as a biomimetic. Sci World J. 2003;3:138-55.

9. Avery NC, Bailey AJ. Restraining cross-links responsible for the mechanical properties of collagen fibers: natural and artificial, Collagen. Boston: Springer; 2008. p. 81-110.

10. Zhang Y, Mansel BW, Naffa R, Cheong S, Yao Y, Holmes G, Chen HL, Prabakar S. Revealing molecular level indicators of collagen stability: minimizing chrome usage in leather processing. ACS Sustain Chem Eng. 2018;6(5):7096-104. 
11. Eyre DR. An automated method for continuous-flow analysis of radioactivity applicable to the study of collagen crosslinks. Anal Biochem. 1973;54(2):619-23.

12. Wess TJ, Miller A, Bradshaw JP. Cross-linkage sites in type I collagen fibrils studied by neutron diffraction. J Mol Biol. 1990;213(1):1-5.

13. Sims TJ, Avery NC, Bailey AJ. Quantitative determination of collagen crosslinks. Extracellular matrix protocols. Totowa: Humana Press; 2000. p. $11-$ 26.

14. Black D, Duncan A, Robins SP. Quantitative analysis of the pyridinium crosslinks of collagen in urine using ion-paired reversed-phase highperformance liquid chromatography. Anal Biochem. 1988;169(1):197-203.

15. Paschalis EP, Ilg A, Verdelis K, Yamauchi M, Mendelsohn R, Boskey AL. Spectroscopic determination of collagen cross-links at the ultrastructural level and its application to osteoporosis. Bone. 1998;23(Suppl):S342.

16. Paschalis EP, Gamsjaeger S, Tatakis DN, Hassler N, Robins SP, Klaushofer K. Fourier transform infrared spectroscopic characterization of mineralizing type I collagen enzymatic trivalent cross-links. Calcif Tissue Int. 2015;96(1):18-29.

17. Gamsjaeger S, Robins SP, Tatakis DN, Klaushofer K, Paschalis EP. Identification of pyridinoline trivalent collagen cross-links by Raman microspectroscopy. Calcif Tissue Int. 2017;100(6):565-74.

18. Khalid M, Bora T, Al Ghaithi A, Thukral S, Dutta J. Raman spectroscopy detects changes in bone mineral quality and collagen cross-linkage in staphylococcus infected human bone. Sci Rep. 2018;8(1):9417.

19. Naffa R, Maidment C, Holmes G, Norris G. Insights into the molecular composition of the skins and hides used in leather manufacture. J Am Leather Chem Assoc. 2019;114(1):29-37.

20. Bacon GE. Neutron diffraction, vol. 3; 1975

21. White JW, Miller A, Ibel K. Neutron diffraction studies on collagen. Journal of the chemical society, faraday transactions 2: molecular and. Chem Phys. 1976:72:435-8.

22. Hulmes DJ, Miller A, White SW, Timmins PA, Berthet-Colominas C. Interpretation of the low-angle meridional neutron diffraction patterns from collagen fibres in terms of the amino acid sequence. Int J Biol Macromol. 1980;2(6):338-46.

23. Bonar LC, Lees $S$, Mook HA. Neutron diffraction studies of collagen in fully mineralized bone. J Mol Biol. 1985;181(2):265-70.

24. Wess TJ, Wess L, Miller A, Lindsay RM, Baird JD. The in vivo glycation of diabetic tendon collagen studied by neutron diffraction. J Mol Biol. 1993; 230(4):1297-303.

25. Skakle JM, Aspden RM. Neutron diffraction studies of collagen in human cancellous bone. J Appl Crystallogr. 2002;35(4):506-8.

26. Bailey $\mathrm{AJ}$, Peach CM. Isolation and structural identification of a labile intermolecular crosslink in collagen. Biochem Biophys Res Commun. 1968; 33(5):812-9.

27. Naffa R, Holmes G, Zhang W, Maidment C, Shehadi I, Norris G. Comparison of liquid chromatography with fluorescence detection to liquid chromatography-mass spectrometry for amino acid analysis with derivatization by 6-aminoquinolyl-N-hydroxysuccinimidyl-carbamate: applications for analysis of amino acids in skin. Arab J Chem. 2019. https:// www.sciencedirect.com/science/article/pii/S1878535219300474

28. Kliment CR, Englert JM, Crum LP, Oury TD. A novel method for accurate collagen and biochemical assessment of pulmonary tissue utilizing one animal. Int J Clin Exp Pathol. 2011:4(4):349.

29. Maynes R. Structure and function of collagen types. Amsterdam: Elsevier; 2012

30. Wood K, Mata JP, Garvey CJ, Wu CM, Hamilton WA, Abbeywick P, Bartlett D, Bartsch F, Baxter P, Booth N, Brown W. QUOKKA, the pinhole small-angle neutron scattering instrument at the OPAL research reactor, Australia: design, performance, operation and scientific highlights. J Appl Crystallogr. 2018;51(2):294-314.

31. Kline SR. Reduction and analysis of SANS and USANS data using IGOR pro. J Appl Crystallogr. 2006;39(6):895-900.

32. Ingham B, Li H, Allen EL, Toney MF. SAXSFit: A program for fitting small-angle X-ray and neutron scattering data. arXiv preprint arXiv:0901.4782; 2009.

33. Zhang $Y$, Snow T, Smith AJ, Holmes G, Prabakar S. A guide to highefficiency chromium (III)-collagen cross-linking: synchrotron SAXS and DSC study. Int J Biol Macromol. 2019;126:123-9.

34. Eyre DR, Weis M, Rai J. Analyses of lysine aldehyde cross-linking in collagen reveal that the mature cross-link histidinohydroxylysinonorleucine is an artifact. J Biol Chem. 2019;294(16):6578-90.

35. Tanzer ML, Housley T, Berube L, Fairweather R, Franzblau C, Gallop PM. Structure of two histidine-containing cross-links from collagen. J Biol Chem. 1973;248(2):393-402.
36. Bernstein PH, Mechanic GL. A natural histidine-based imminium cross-link in collagen and its location. J Biol Chem. 1980:255(21):10414-22.

37. Bailey AJ, Lister D. Thermally labile cross-links in native collagen. Nature. 1968:220(5164):280.

38. Bailey AJ, Peach CM. Identification of a labile intermolecular cross-link in collagen. Biochem J. 1969;111(3):12-3.

39. Bailey AJ, Peach CM. The chemistry of the collagen cross-links. The absence of reduction of dehydrolysinonorleucine and dehydrohydroxylysinonorleucine in vivo. Biochem J. 1971;121(2):257-9.

40. Zhang Y, Ingham B, Leveneur J, Cheong S, Yao Y, Clarke DJ, Holmes G, Kennedy J, Prabakar S. Can sodium silicates affect collagen structure during tanning? Insights from small angle X-ray scattering (SAXS) studies. RSC Adv. 2017;7(19):11665-71.

41. Zhang Y, Ingham B, Cheong S, Ariotti N, Tilley RD, Naffa R, Holmes G, Clarke DJ, Prabakar S. Real-time synchrotron small-angle X-ray scattering studies of collagen structure during leather processing. Ind Eng Chem Res. 2017;57(1):63-9.

42. Naffa R. Understanding the molecular basis of the strength differences in skins used in leather manufacture (Doctoral dissertation). 2017. Retrieved from https://mro.massey.ac.nz/handle/10179/13154

43. Sears VF. Neutron scattering lengths and cross sections. Neutron News. 1992;3(3):26-37.

44. Yamanishi $H$, Sato $Y$. The removal of non-collagen components from newborn calf dermis with magnesium chloride solution. J Biochem. 1976; 79(1):131-44.

45. Wess TJ, Wess $L$, Miller $A$. The in vitro binding of acetaldehyde to collagen studied by neutron diffraction. Alcohol Alcohol. 1994;29(4):403-9.

46. Ripamonti A, Roveri N, Braga D, Hulmes DJ, Miller A, Timmins PA. Effects of $\mathrm{pH}$ and ionic strength on the structure of collagen fibrils. Biopolymers. 1980; 19(5):965-75

47. Schoenborn BP, editor. Neutron Scattering for the Analysis of Biological Structures: Report of Symposium Held June 2-6, 1975. New York: Biology Department, Brookhaven National Laboratory; 1976.

\section{Publisher's Note}

Springer Nature remains neutral with regard to jurisdictional claims in published maps and institutional affiliations.

\section{Submit your manuscript to a SpringerOpen ${ }^{\odot}$ journal and benefit from:}

- Convenient online submission

- Rigorous peer review

- Open access: articles freely available online

- High visibility within the field

- Retaining the copyright to your article

Submit your next manuscript at $>$ springeropen.com 